\title{
Application of International Freight Simultaneous Transportation Equilibrium Model to Sultanate of Oman
}

\author{
Mohamad K. Hasan \\ Department of Quantitative Methods and Information Systems College of Business Administration, \\ Kuwait University, Safat, Kuwait \\ Email:mkamal@cba.edu.kw
}

How to cite this paper: Hasan, M.K. (2017) Application of International Freight Simultaneous Transportation Equilibrium Model to Sultanate of Oman. Journal of Service Science and Management, 10, 559-586.

https://doi.org/10.4236/jssm.2017.106043

Received: November 29, 2017

Accepted: December 25, 2017

Published: December 28, 2017

Copyright $\odot 2017$ by author and Scientific Research Publishing Inc. This work is licensed under the Creative Commons Attribution International License (CC BY 4.0).

http://creativecommons.org/licenses/by/4.0/

\begin{abstract}
An implementation of the International Freight Simultaneous Transportation Equilibrium Model (IFSTEM) that developed in United Nations Economic and Social Commission for Western Asia (ESCWA), to the goods trade through the ports and lands of Sultanate of Oman is presented. Although some socio-economic variables, which are not available, were required for IFSTEM model calibration, some reasonable assumptions were made and it was good enough to draw the following main findings: the proposed alternative enhancement scenarios were four nested scenarios, i.e., each scenario included the previous one plus an additional enhancement. These four enhancement scenarios were analyzed against and compared with scenario (0), i.e., the reference "do nothing" scenario. The prediction results revealed that the estimated international trade flows (imports, exports and re-exports) for Oman were increased by more than $504 \%$ by 2040 compared to the present situation of the base year 2012. This increase would represent around 70\% compared to the "do nothing" reference scenario by the year 2040 assuming that the average increase of international trade flows in the "do nothing" case would be around $4 \%$ annually during the analysis period from 2012 to 2040 . The predictions of average total trip time and total cost per ton revealed an estimated decrease, compared to the reference scenario, by around $25 \%$ and $20 \%$ respectively. These results are internally consistent and represented reasonably significant improvements compared to the "do nothing" reference scenario.
\end{abstract}

\section{Keywords}

International Multimodal Multicommodity Network, Simultaneous Transportation Network Equilibrium Model, Integrated Transport 
Network, Integrated Transport System, International Freight Transport, Exporters, Importers

\section{Introduction}

The prediction of multicommodity freight flows over a multimodal network has attracted much interest in the recent years. In contrast to urban transportation, where the prediction of passenger flows over multimodal networks has been studied extensively and many of the research results have been transferred to practice (Safwat and Walton [1], Safwat and Hasan [2], Safwat [3] and [4], Safwat and Magnanti [5], Hasan [6], Hasan and Al-Gadhi [7], Hasan and Safwat [8], Florian [9] and [10]), the study of freight flows at the national, regional, or international level, perhaps due to the inherent difficulties and complexities of such problems, received less attention. A good review of freight transport modeling may be found in Friez and Harker. Below is a brief review based on Guelat et al.

The first class of models that was well studied in the past for prediction of interregional freight flows is the spatial price equilibrium model and its variants. The model, stated initially by Samuelson [11] and extended by Takayama and Judge [12] [13] then by Florian and Los [14], Friesz, Tobin and Harker [15], has been used extensively for analyzing interregional commodity flows. This class of models determines simultaneously the flow between the producing and consuming regions as well as the selling and buying prices. The transportation network is usually modeled in a simplistic way (bipartite network) and these models rely to a large extent on the supply and demand functions of the producers and consumers respectively. The calibration of these functions is essential to the application of these models and the transportation costs are unit costs or may be functions of the flow on the network. There have been so far a few multicommodity applications of this class of models, with the majority of applications having been carried out in agricultural and energy sectors in an international or interregional setting. It is not this class of models which is the main topic of our study.

The second class of models which we consider are freight network equilibrium models which enable the prediction of multicommodity flows over a multimodal network, where the physical network is modeled at a level of detail appropriate for a nation or a large region, and represents the physical facilities with relatively little abstraction. The demand for the transportation services is exogenous and may originate from an input-output model, if one is available, or from other sources, such as observed demand or scaling of observed past demand (in our proposed model endogenous transportation demand will be considered). The choice of mode or subsets of modes used is exogenous and intermodal shipments are permitted. In this sense, these models may be integrated with 
econometric demand models as well. The emphasis is on network representation and the proper representation of congestion effects in a static model aimed to serve comparative studies or discrete time multiperiod analyses.

The first significant multimodal predictive freight network model was by Roberts [16] and later extended by Kresge and Roberts [17]. This model became known as the Harvard-Brookings model. Only the behavior of shippers was taken into account. Using constant unit costs, each shipper chooses the shortest path for movements from an origin to a destination. The amount moving between an origin-destination (O-D) pair being determined by a simple distribution submodel. The model resorted to a fairly simple "directed link" representation of the physical network and congestion effects were not considered. The model was applied to the transport network of Columbia.

Later, the Multi-State Transportation Corridor Model (McGinnis et al. [18], Jones and Sharp [19] and Sharp [20]) went a step further in representing an explicit multimodal network, but without any consideration of congestion. The first model that considers congestion effects and shipper-carrier interaction is that of Friesz et al. [21]. A review of shipper-carrier models, both sequential and simultaneous, is given by Friesz and Harker [22]. The first application of a model that considers congestion phenomena in this field is the Freight Network Equilibrium Model (FNEM) (Friesz et al. [23]). This is a sequential model which uses two network representations : an aggregate network that is perceived by the users, which serves to determine the carriers chosen by the shippers and then more detailed separate networks for each carrier, where commodities are transported by minimizing total cost. A generalization of the work of Friesz et al. [21] in which variable demand functions are considered in the shipper's submodels, is given by Harker and Friesz [24] and [25]. They combine the variable demand modeling approach of spatial equilibrium models with a detailed description of the behavior of shippers and carriers, in mathematical formulations that are yet to be tested in a practical application.

Guelat, et al. [26] developed a multimodal multiproduct network assignment model that does not consider shippers and carriers as distinct actors in the decision made for shipping freight. This level of aggregation which is appropriate for strategic planning of freight flows, where origins and destinations correspond to relatively large geographical areas, leads to the specification of supplies and demands for the products considered, which represent the services provided by all the individual shippers for the same product. Their model assumes that goods are shipped at minimum total generalized cost, which is particularly appropriate when certain products are captive to a mode, or a subset of modes, due to service availability or regulation. In other situations, as in our study, when modes compete for the shipment of products, generalized cost function components which reflect shippers' objective should be included. This generalized cost may be composed of costs, time delays or other relevant factors, keeping in mind that shippers, in this context, are 
aggregated by origins. The multimodal aspects of their model are accounted for in the network representation chosen and the multiproduct aspects are accounted for in the formulation of the predictive model and are taken advantage of in the solution procedure.

Safwat [27] describes in his dissertation an intercity transportation model, i.e., a Simultaneous Transportation Equilibrium Model (STEM). An application of the STEM model to Egypt included both passenger and freight movement. The generation of trips in a region is incorporated via a specific non-linear functional form including transportation costs (see also Safwat and Magnanti [5]). Thus, Safwat represented producers' and consumers' behavior by this specific trip generation function, collapsing their decision-process into one known functional relationship. In practice, the STEM model was applied to many real-world transportation systems. The most recent applications were on the urban transportation network of Tyler, Texas, U.S.A. (Hasan and Safwat [8]) and of Riyadh, Saudi Arabia (Hasan and Al-Gadhi [7]). Earlier applications included the intercity passenger travel in Egypt (Safwat [3] and [4]) and the urban transportation network of Austin, Texas, U.S.A. (Safwat and Walton [1]). Moavenzadeh et al. [28] included an extended version of the STEM model as a central component of a comprehensive methodology for intercity transportation planning in Egypt [29]. This methodology has been used in several case studies involving multimodal transportation of passengers and freight in Egypt.

Safwat and Hasan [30] further adapted the STEM to International Freight STEM (i.e., IFSTEM) and implemented it to the Integrated Transport System in the Arab Mashreq (ITSAM) through United Nations Economic and Social Commission for Western Asia (UN-ESCWA).

Hasan [31] implemented and adapted the IFSTEM methodology to the international trade flows through Lebanon, Syria and Jordan. Throughout these applications, STEM and IFSTEM predictions consistently outperformed the predictions produced by applying the traditional sequential transport planning approach used worldwide by international consultants.

More recently, Mathisena and Hanssena [32] give a good academic literature on intermodal freight transport. First, they examined the historical development of academic research on intermodal freight transport. Second, they identified the seminal works on the topic.

Duan et al. [33] demonstrate the effect of recognizing heterogeneity in values of time (VOT) on the design of a hub network for freight transportation. By taking the VOT distribution into account, we emphasize shippers' broader logistical, social and economic situation in the network design, and are not limited to commodity types.

The IFSTEM-Oman adapted in this paper is essentially based on the above mentioned developments, adaptations and implementations. That is, the IFSTEM-Oman is a simultaneous trip generation, trip distribution, modal split and traffic assignment model that most appropriately illustrates the behavior of 
exporters and importers of different commodities over the international multimodal network for Oman.

The remainder of this article is structured as follows: In Section 2, we describe the international trade flows prediction model for Oman (IFSTEM-Oman Model); Then, in Section 3, IFSTEM-Oman model application assumptions are presented before predicted international trade flows, times and costs: application results and analysis are presented in Section 4; Finally, conclusions are presented in Section 5.

\section{The International Trade Flows Prediction Model for Oman (IFSTEM-Oman Model)}

Hasan [31] and Safwat and Hasan [30] described in details the basic functions and assumptions of the International Freight Simultaneous Transport Equilibrium Model (IFSTEM).

The IFSTEM Model may be briefly described as follows:

$$
\begin{aligned}
& S_{i}^{r}=\max \left\{0, \ln \sum_{j \in D_{i}^{r}} \exp \left(-\theta_{i}^{r} u_{i j}^{r}+A_{j}^{r}\right)\right\}, \forall i \in I^{r} \\
& G_{i}^{r}=\alpha^{r} S_{i}^{r}+E_{i}^{r}, \forall i \in I^{r} \\
& T_{i j}^{r}=\left\{\begin{array}{ll}
G_{i}^{r} \frac{\exp \left(-\theta_{i}^{r} u_{i j}^{r}+A_{j}^{r}\right)}{\sum_{k \in D_{i}^{r}} \exp \left(-\theta_{i}^{r} u_{i k}^{r}+A_{k}^{r}\right)} & \text { if } i m c \geq 0 \\
0 & \text { otherwise }
\end{array}, \forall i j \in R^{r}\right. \\
& C_{p}^{r}\left\{\begin{array}{l}
=u_{i j}^{r} \text { if } H_{p}^{r}>0 \\
\geq u_{i j}^{r} \text { if } H_{p}^{r}=0
\end{array}, \forall p \in P_{i j}^{r}, i j \in R^{r}\right. \\
& C_{p}^{r}=\sum_{a \in A^{r}} \delta_{a p}^{r} C_{a}^{r}\left(F_{a}^{r}\right), \forall p \in P_{i j}^{r}, i j \in R \\
& \delta_{a p}^{r}=\left\{\begin{array}{ll}
1 & \text { if link a belongs to path } p \\
0 & \text { otherwise }
\end{array}, \forall p \in P_{i j}^{r}, i j \in R^{r}\right.
\end{aligned}
$$

where

$C=$ Set of all commodity types;

$M=$ Set of all mode types;

$O=$ Set of all ALO (Administrative and Logistics Opeerations) types;

$(N, A)=$ A multimodal multi-commodity network consisting of a set of $N$ nodes and a set of $A$ links where: $N=\bigcup_{r \in C} r \in C$ and $A=\bigcup_{r \in C} A^{r}$;

$I=$ Set of origin (export) nodes $I=\bigcup I^{r}$ and $N^{r} \supseteq I^{r}$;

$i=$ An origin (export) node in the set $I$;

$r$ = The commodity type;

$D_{i}^{r}=$ Set of destination (import) nodes that are feasible for importing commodity $r$ from origin $i$;

$j=$ A destination (import) node in the set $D_{i}^{r} ;$ 
$p$ = A simple (i.e., no node repeated) multimodal path (i.e., it may include a combination of links with different modes);

$R^{r}=$ Set of origin-destination pairs $(i j)$ for commodity $r$;

$R$ = Set of all origin-destination pairs (ij) in the system, where $R=\bigcup R^{r}$;

$P_{i j}^{m(r)}=$ Set of simple paths that can be used to transport commodity $r^{r}$ from origin $i$ to destination $j$ using only $m(r)$ modes of transport;

$P^{r}=$ Set of simple paths in the network $\left(N^{r}, A^{r}\right)$, i.e., $\left(P^{r}=\bigcup_{i j \in R^{r}} P_{i j}^{m(r)}\right)$;

$a=\mathrm{A}$ link in the set $A$. Each link is identified by $(k, l, q)$, i.e., the link connects node $k$ to node $l$ by mode/operation $q$;

$A_{j}^{r}=$ a composite measure of the effect that the socioeconomic variables, which are exogenous to transport system, have on the number of tons of commodity $r$ imported at destination $j$;

$S_{i}^{r}=$ accessibility of exporter of commodity $r$ at origin $i$;

$G_{i}^{r}=$ the total number of tons of commodity $\mathrm{r}$ exported from origin $i$;

$E_{i}^{r}=$ a composite measure of the effect that the socioeconomic variables, which are exogenous to the transport system, have on the number of tons of commodity $r$ exported from origin $i$;

$T_{i j}^{r}=$ the number of tons of commodity $r$ exported from origin $i$ to a destination $j$;

$u_{i j}^{r}=$ the "perceived" delivery cost (price) of the commodity $r$ exported from origin $i$ and imported to destination $j$;

imc $=S P_{j}^{r}-u_{i j}^{r}-M P_{j}^{r} \geq 0=$ the import criteria;

$S P_{j}^{r}=$ the average selling price of commodity $r$ that an importer at destination $j$ knew it;

$M P_{j}^{r}=$ a margin profit of commodity $r$ that an importer specified it;

$H_{p}^{r}=$ the flow of commodity $r$ on multimodal path $p$ and the link-path incidence relationships are given by $F_{a}^{r}=\sum_{p \in P^{r}} \delta_{a p}^{r} H_{p}^{r}, \forall a \in A^{r}$;

$C_{p}^{r}=$ the total perceived delivery cost for commodity $r$ from export origin node $i$ to import destination node $j$ on any multimodal path $p$, which is the sum of the perceived costs on the links, $C_{a}^{r}\left(F_{a}^{r}\right)$, that comprise that multimodal path.

\subsection{Equivalent Optimization Problem (EOP) for IFSTEM}

The IFSTEM model can be formulated as the following EOP for each commodity $r \in C$ :

$$
\begin{aligned}
\text { Minimize } Z(S, T, H)= & \sum_{i \in I^{r}} \frac{1}{\theta_{i}^{r}}\left[\frac{\alpha^{r}}{2}\left(S_{i}^{r}\right)^{2}+\alpha^{r} S_{i}^{r}-\left(\alpha^{r} S_{i}^{r}+E_{i}^{r}\right) \ln \left(\alpha^{r} S_{i}^{r}+E_{i}^{r}\right)\right] \\
& +\sum_{i \in I^{r}} \frac{1}{\theta_{i}^{r}}\left[\sum_{j \in D^{r}}\left[T_{i j}^{r} \ln T_{i j}^{r}-A_{j}^{r} T_{i j}^{r}-T_{i j}^{r}\right]\right]+\sum_{a \in A^{r}} \int_{0}^{F_{a}^{r}} C_{a}^{r}(w) \mathrm{d} w
\end{aligned}
$$

Subject to: 


$$
\begin{gathered}
\sum_{j \in D_{i}^{r}} T_{i j}^{r}=\alpha^{t} S_{i}^{r}+S_{i}^{r}, \quad \forall i \in I^{r} \\
\sum_{p \in P_{i j}^{r}} H_{p}^{r}=T_{i j}^{r}, \quad \forall i j \in R \\
S_{i}^{r} \geq 0, \quad \forall i \in I^{r} \\
T_{i j}^{r} \geq 0, \quad \forall i j \in R^{r} \\
H_{p}^{r} \geq 0, \quad \forall p \in p^{r}
\end{gathered}
$$

where

$$
F_{a}^{r}=\sum_{p} \delta_{a p}^{r} H_{P}^{R}, \quad \forall p \in p^{r} .
$$

\subsection{The Solution Procedure for EOP}

We need an efficient solution procedure for the EOP that is guaranteed to converge to an existing and unique equilibrium. Safwat and Brademeyer [34] developed a globally convergent efficient algorithm called the Logit Distribution of Trips (LDT) algorithm for predicting equilibrium on the STEM model. We adapted this algorithm to solve our IFSTEM. The algorithm belongs essentially to the class of feasible-direction methods and is known to be globally convergent. For each commodity, at any given iteration, $k$, the method involves three main steps:

1) determines a direction for improvement, $d^{k}$;

2) Determines an optimum step size, $\lambda^{k}$, along that direction;

3) Updates the current solution, $X^{k}, X^{k+1}=X^{k}+\lambda^{k} d^{k}$ where the vector $X^{k}$ is defined by $X^{k}=\left(S^{k}, T^{k}, F^{k}\right)$.

As mentioned in the network representation of Safwat and Hasan (2004) and Hasan (2009), each O-D pair for a given commodity will have its own network, therefore the algorithm will deal with each O-D pair network separately and then updates its flows to the commodity network level. The algorithm can be summarized as follows:

\section{Solution Algorithm:}

\section{Step 0: Initialization.}

Perform all-or-nothing assignment based on $C_{a}=C_{a}(0), \in a \in A$ (i.e., free flow cost). This yield $X^{1}=\left(S^{1}, T^{1}, F^{1}\right)$. Set. $k=1$.

\section{Step 1: Cost update.}

Set $C_{a}^{k}=C_{a}\left(F_{a}^{k}\right), \forall a \in A$.

\section{Step 2: Direction finding.}

Compute the costs on the shortest paths $u_{i j}^{k}, \forall i j \in R$ based on $C_{a}^{k}$. Find $d^{k}=Y^{k}-X^{k}$ where the vector $Y^{k}=\left(L^{k}, Q^{k}, V^{k}\right)$ is given by

$$
L_{i}^{k}=\max \left\{0, \ln \sum_{j \in D_{i}} \exp \left(-\theta_{i} u_{i j}^{k}+A_{j}\right)\right\}, \quad \forall i \in I
$$




$$
\begin{aligned}
& Q_{i j}^{k}=\left\{\begin{array}{ll}
\frac{\left(\alpha L_{i}^{k}+E_{i}\right) \exp \left(-\theta_{i} u_{i j}^{k}+A_{j}\right)}{\sum_{l \in D_{i}} \exp \left(-\theta_{i} u_{i l}^{k}+A_{l}^{k}\right)} & \text { if } \text { imc }=S P_{j}-u_{i j}^{k}-M P_{j} \geq 0 \\
0 & \text { otherwise }
\end{array}, \forall i j \in R\right. \\
& V_{a}^{k}=\sum_{i j \in R} \sum_{p \in P_{i j}} \delta_{p} B_{p}^{k}, \quad \forall a \in A
\end{aligned}
$$

where

$$
B_{p}^{k}=\left\{\begin{array}{ll}
Q_{i j}^{k} & \text { if } p=p^{*} \in P_{i j} \\
0 & \text { otherwise }
\end{array}, \forall p \in P_{i j}, \forall i j \in R \text { and } p^{*}\right. \text { is the shortest path }
$$

between the given O-D pair. Then the feasible direction at iteration $k$ is the vector $d^{k}$ with the following components:

$$
\begin{gathered}
d_{i}^{k}=L_{i}^{k}-S_{i}^{k}, \quad \forall i \in I \\
d_{i j}^{k}=Q_{i j}^{k}-T_{i j}^{k}, \quad \forall i j \in R \\
d_{a}^{k}=V_{a}^{k}-F_{a}^{k}, \quad \forall a \in A
\end{gathered}
$$

Step 3: Line search.

Find $\lambda^{k}$ that solve

$$
\begin{aligned}
& \sum_{i \in I} \frac{\alpha}{\theta_{i}}\left[\left(S_{i}^{k}+\lambda d_{i}^{k}\right)-\ln \left(\left(S_{i}^{k}+\lambda d_{i}^{k}\right)+E_{i}\right)\right] d_{i}^{k}+\sum_{i j \in R} \frac{1}{\theta_{i}}\left[\ln \left(T_{i j}^{k}+\lambda d_{i j}^{k}\right)-A_{j}\right] d_{i j}^{k} \\
& +\sum_{a \in A} C_{a}\left(F_{a}^{k}+\lambda d_{a}^{k}\right) d_{a}^{k}=0
\end{aligned}
$$

\section{Step 4: Move.}

Set.

$$
\begin{array}{ll}
S_{i}^{k+1}=S_{i}^{k}+\lambda^{k} d_{i}^{k}, & \forall i \in I \\
T_{i j}^{k+1}=T_{i j}^{k}+\lambda^{k} d_{i j}^{k}, \quad \forall i j \in R \\
F_{a}^{k+1}=F_{a}^{k}+\lambda^{k} d_{a}^{k}, \quad \forall a \in A
\end{array}
$$

\section{Step 5: Convergence test.}

If a convergence criterion is met, stop (the current solution $\left\{S_{i}^{k+1}, T_{i j}^{k+1}, F_{a}^{k+1}\right\}$ is the set of equilibrium flow patterns); otherwise, set $k=k+1$ and go to Step 1 .

A computer code in $\mathrm{C}++$ was developed to create the multimodal network representation requirements and solve the above Algorithm.

\section{IFSTEM-Oman Model Application Assumptions}

\subsection{Application Assumptions for Demand Models}

As can be seen from the description of the IFSTEM Model, it involves two demand models. These are trip generation and trip distribution models. In a typical application of the IFSTEM Model, these demand models would have been calibrated using available socio-economic and transport and logistics cost data. However, because of data limitation on the availability of socio-economic and transport and logistics cost variables, in this application of the IFSTEM-Oman 
Model, we could not perform typical calibration of these demand models.

Instead, however, we assumed the following assumptions to "calibrate" the trip generation and trip distribution models within the IFSTEM-Oman Model. First, we invoked the following assumptions to estimate the exogenous variables $E_{i}$ for each origin $i$ from the equation

$$
E_{i}=\sum_{l=1}^{L} \alpha_{l} q_{l}\left(E_{l i}\right)
$$

1) $l=1$;

2) $q_{l}\left(E_{l i}\right)=E_{1 i}=G_{i}^{o} \quad($ Observed trip generation at origin $i)$;

3) $\alpha_{1}=0.40$ for all origins.

Hence

$$
E_{i}^{o}=0.40 G_{i}^{o}, \quad \forall i \in I
$$

That is, the socio-economic variables, which are exogenous to the transport and logistics system, are assumed to account for $40 \%$ of the international trade flows that are exported from that origin.

For the attractiveness measure in the trip distribution model,

$$
A_{j}=\sum_{w=1}^{W} \theta_{i w} g_{w}\left(A_{w j}\right)
$$

We assumed that

$$
A_{i j}=\ln T_{i j}^{o}, \quad \forall i j \in R
$$

By this assumption each destination has different attractiveness for different origins. We then assumed that this attractiveness composite measure is the exogenous variable in the exporter observed utility function. That is,

$$
V_{i j}=-\theta_{i} u_{i j}+A_{i j}
$$

We further assumed that the exporter at origin $i$ is influenced only by this attractiveness measure and that he would not consider the delivery cost $u_{i j}$ to be a major factor in his choice of the destination.

Hence, the accessibility measure for this behavior will be

$$
\begin{gathered}
S_{i}^{o}=\ln \sum_{j \in D_{i}} \exp \left(-\theta_{i} u_{i j}+A_{i j}\right), \quad \forall i \in I \\
S_{i}^{o}=\ln \sum_{j \in D_{i}} \exp \left(\ln \left(T_{i j}^{o}\right)\right), \quad \forall i \in I \\
S_{i}^{o}=\ln G_{i}^{o}, \quad \forall i \in I
\end{gathered}
$$

And the trip generation model will be specified as follows:

$$
\begin{gathered}
G_{i}^{o}=\alpha_{i} S_{i}^{o}+E_{i}^{0}, \quad \forall i \in I \\
G_{i}^{o}=\alpha_{i} \ln \left(G_{i}^{o}\right)+0.40 G_{i}^{0}, \quad \forall i \in I
\end{gathered}
$$

Now we can estimate $\alpha_{i}, \forall i \in I$ from the observed trip generation as follows:

$$
\alpha_{i}=\frac{0.6 G_{i}^{o}}{\ln \left(G_{i}^{o}\right)}, \forall i \in I
$$


We then estimated the parameters $\theta_{i}^{r}=\theta^{r}$ for all origins of commodity $r$ by solving the IFSTEM-Oman Model for different values for $\theta^{r}$ until we obtain the values $\theta^{r}$ that satisfy the following condition:

$$
\frac{\sum_{i \in I} G_{i}^{o}}{\sum_{i \in I} G_{i}^{p}} \approx 1.60 \text { for each commodity }
$$

where $G_{i}^{p}$ is the predicted trip generation for origin $i$ for year 2012. This value of $\theta^{r}$ will keep the effect of transport and logistics system (supply), as measured by the delivery cost $u_{i j}$, on the predicted trip generated from origin $\mathrm{i}$ to be $60 \%$ on average less than the observed trip generation.

This is consistent with the earlier assumption that $40 \%$ of trip generation is influenced by socioeconomic factors, which implies that $60 \%$ is influenced by transport and logistics cost factors.

\subsection{IFSTEM-Oman Model Supply Side Assumptions}

The supply side of IFSTEM-Oman Model is represented by a set of link cost functions for different modes and operations. We assumed the following link cost function

$$
C_{a}\left(F_{a}\right)=(c+v t) F_{a}
$$

where

$F_{a}=$ number of tons on link $a$;

$C_{a}\left(F_{a}\right)=$ cost of $F_{a}$ tons in USD;

$c=$ cost per ton in USD;

$t$ = time in days;

$v=$ the value of time per ton per day.

Based on interviews with freight forwarders, we estimated the values of time (see Duan et al. [33]) to be as follows:

For exports 3.5 USD/Tone/Day, for imports 5 USD/Tone/Day, and for Re-exports 7.5 USD/Tone/Day.

\subsection{Input Data for IFSTEM-Oman Model and Application Assumptions}

\subsubsection{Major Seaports and Land Border Points}

According to the available statistics for imports, exports and re-exports for Oman during the base year of 2012, the international trade volumes (available for imports, exports and re-exports) at three major seaports and two major land border points represented around $74 \%$ of the total weight in tons of Omani exports, imports and re-exports and around $90 \%$ of the total value of these observed international trade statistics for Oman. Hence, in this application we considered these major five points of entry/exit of international trade to/from Oman. These are three major seaports, namely Mina Sultan Qaboos (at Muscat), Mina Sohar and Mina Salalah (see Figure 1 and two major land border points, namely Al Wajajah and Wadi Jizzi. From these five points we selected the five commodities of the highest volumes of trade with Oman. 


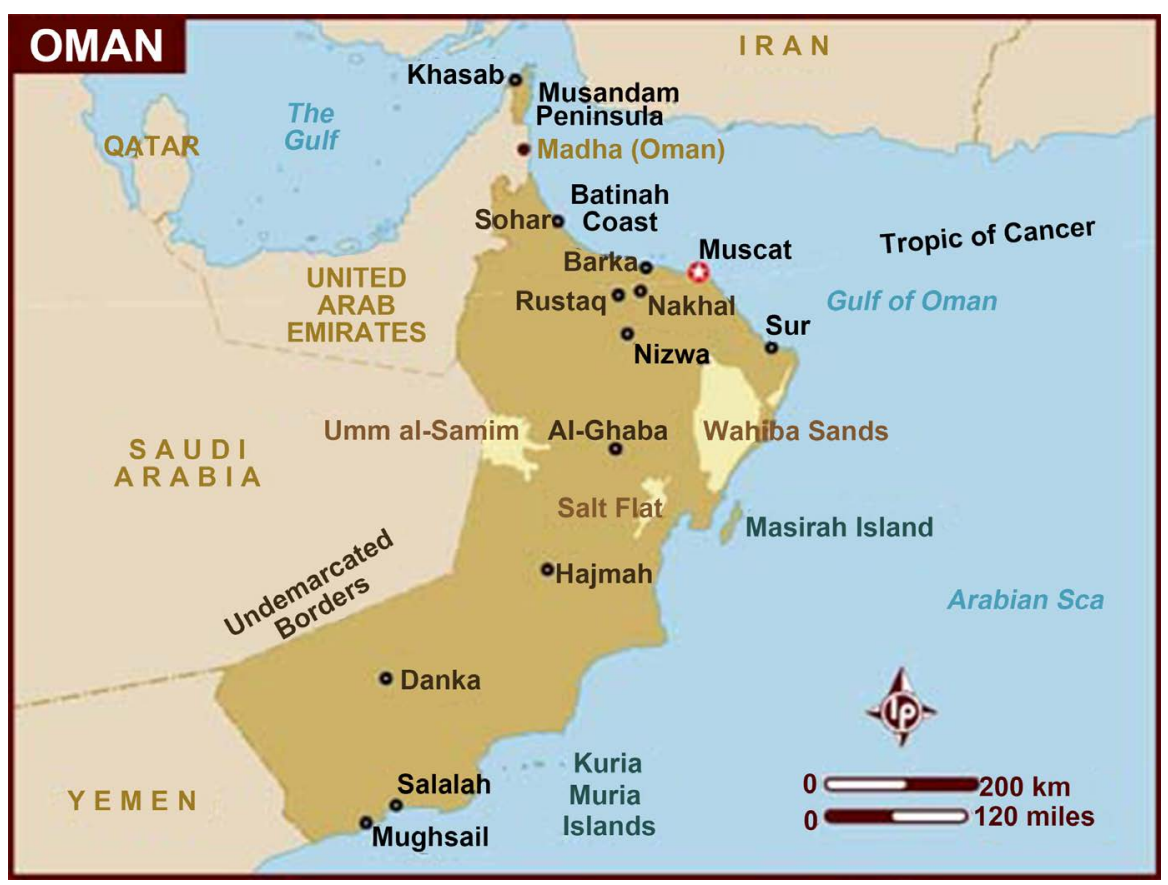

Figure 1. Oman major seaports.

\subsubsection{Observed International Trade Data for 2012}

We obtained the following Import, Export and Re-Export Data for 2012 from the Omani National Centre for Statistics:

1) Commodity H.S Code (4 Digits);

2) Commodity Type;

3) Point of Entry;

4) Country of Export;

5) Observed Flows (in Kilogram and in Value of Omani Rial (OR)).

\subsubsection{Estimated Documents, Times and Costs for International Trade for} 2012

We obtained the following estimates of documents, times and costs of a typical 20-ft container for exports and imports, from the World Bank (WB) Report 2013 on Trading Across Borders (i.e., estimates for the year 2012) for Oman and UAE:

1) Documents to Export (number);

2) Time to Export (days);

3) Cost to Export (USD per 20-ft container);

4) Documents to Import (number);

5) Time to Import (days);

6) Cost to Import (USD per 20-ft container).

We then assumed that the estimates for re-exports of Documents, Times, and Costs are the same as those estimated for Exports according to the WB report indicated above (see Table A1-1 and Table A1-2 in Appendix 1). We estimated the Import, Export and Re-Export Times and Costs for Inland Transport and Handling inside Oman and between Oman and the neighboring land connected 
Arab countries, based on the WB Trading Across Borders Report 2013 (see Table A1-3 and Table A1-4 in Appendix 1).

\subsubsection{Estimated International Maritime Transport Times and Costs for 2012}

We obtained estimates for the International Maritime Transport Times (in days) and Costs (in USD per 20-ft container) for 2012 for Mina Sultan Qaboos from an International Freight Forwarder in Oman. We then assumed that these estimates are the same for Mina Sohar and Mina Salalah simply for lack of data and/or reliable estimates (see TableA1-5 in Appendix 1).

We further assumed that the commodities that go through the land border points Wadi Jizzi or Al Wajajah and not exported or imported from/to UAE, Saudi Arabia, Qatar, Bahrain, Kuwait, Jordan, Syria, and Iraq, will exit/enter from/to Jabil Ali Port in the UAE and their International Maritime Transport Times and Costs to/from other countries worldwide, from/to Jebel Ali Port are $20 \%$ less than the estimated values from/to Mina Sultan Qaboos.

All other commodities that go through the land border points Wadi Jizzi or Al Wajajah and exported or imported from/to UAE, Saudi Arabia, Qatar, Bahrain, Kuwait, Jordan, Syria, and Iraq are assumed to use only land transportation.

\subsubsection{Other Application Assumptions}

Mainly because of lack of appropriate detailed data and actual estimates from the field, we have invoked the previous assumptions and approximate estimates as well as the following general assumptions:

1) All 20 -ft containers carry 10 tons per TEU (10000 KG), as assumed by WB reports.

2) All Points of Entry/Exit in Oman have the same procedures, costs, and times.

3) All Commodities have the same procedures, costs, and times at any Entry/Exit point.

4) Transit and Transhipment trade for Oman are excluded (for lack of data).

\subsubsection{Alternative Enhancement Scenarios}

To achieve the main objectives, our focus has been on undertaking effective and efficient actions with particular focus on significantly improving procedures, times and costs of international trade processes and transactions across Omani ports. In view of the above and the estimates of documents, times and costs for Oman imports and exports as indicated in the WB Trading Across Borders country report 2013, we proposed the first two Scenarios 1 and 2 involving reductions in number of documents and their associated costs as well as port terminal handing times, as indicated in paragraph 5 below.

Considering that an important objective of enhancing Omani ports is to attract major shipping lines to Omani ports. This would contribute significantly to reducing international maritime transport times and costs, and consequently total international trade trip times and costs per ton. The total volumes of interna- 
tional trade with Oman would be expected to increase significantly as well. Hence, we proposed Scenarios 3 and 4 that involve reducing international maritime transport times and costs by $20 \%$ and $40 \%$ respectively. Scenarios 3 and 4 are also inclusive of Scenarios 1 and 2, as indicated in paragraph 5 below.

Based on the estimated GDP growth rate for 2013 (which was approximately $4 \%$ ) we assumed that the average annual growth rate for prediction purposes in our analysis is 4\% annually during the analysis period from 2012 through 2040.

For each scenario we predicted the expected increase in international trade flows of imports, exports and re-exports (in tons), the expected decrease in average total trip time (in days) and the expected decrease in total cost per ton (in USD). The predictions are estimated for the years following the completion of implementation of the alternative enhancement scenarios until the target year of 2040.

Based on the above mentioned assumptions, the description of the five scenarios considered in the analysis are as follows:

- Scenario 0 (2012-2040)

The reference scenario "do nothing" and its prediction to the target year 2040.

- Scenario 1 (2015-2040)

Reduce No. of Documents from 8 to 4 as of the year 2015.

- Scenario 2 (2016-2040)

Scenario 1 plus Reduce Ports \& Terminal Handling Time from 3 days for export and 2 days for import to 1 day for each as of the year 2016.

- Scenario 3 (2017-2040)

Scenario $1 \& 2$ plus Reduce International Maritime Transport Times and Costs for Oman by $20 \%$ as of the year 2017.

- Scenario 4 (2018-2040)

Scenario $1 \& 2$ plus Reduce International Maritime Transport Times and Costs for Oman by $40 \%$ as of year 2018 .

\section{Predicted International Trade Flows, Times and Costs: Application Results and Analysis}

In this section we summarize and analyze the results of the predicted international trade flows, times and costs of imports, exports and re-exports for Oman for all five alternative scenarios (i.e., the reference scenario (Scenario 0 ) and the four alternative enhancement Scenarios 1, 2, 3 and 4). The Appendix includes Tables A2-1-A2-3 that show the results of the IFSTEM-Oman Model predictions. The following paragraphs summarize the analysis of these international trade flows, times and costs results for Oman from the base year of 2012 through the target year of 2040 .

\subsection{The IFSTEM-Oman Model Application}

Based on the assumptions invoked in Section 3 above, the IFSTEM-Oman Model was first used to replicate the current situation (i.e., the reference scenario (0) for base year 2012). The IFSTEM-Oman Model was applied to the 5 entry/exit 
points of Oman (i.e., 3 seaports and 2 land border points as indicated in section 3 ) using the 5 highest volume commodities crossing these points (see Table A1-6 in Appendix 1). The observed international trade flows of imports, exports and re-exports for the selected 5 commodities at these 5 entry/exit points was 811,881 tons.

The Import, Export and Re-Export Data for 2012 obtained from the Omani National Center for Statistics showed that there are 1128 commodities at the five points of entry/exit used in the analysis. The observed flows (volumes) for these 1128 commodities in 2012 were $27,338,746$ tons and for all commodities crossing all points of entry or exit in Oman were 37,112,001 tons.

We then expanded the results of the IFSTEM-Oman Model to all exports, imports, and re-exports for Oman by multiplying the model results by the following expansion factor

$$
\frac{37112001}{811881}=45.71113 .
$$

This simple expansion factor is reasonable and consistent in this particular application of the model since the procedures, times and costs across commodities and entry/exit points in Oman were assumed to be equal. If and when the estimated and collected input data would involve variations among commodities and entry/exit points in Oman, the IFSTEM-Oman Model can then be easily applied to all commodities and all entry/exit points without the need to use an expansion factor.

\subsection{Growth Rates of Future International Trade Flows}

Based on the assumed average annual growth rate of $4 \%$, the predicted international trade flows for any future year $2012+t$ up to the target year 2040 are computed as follows:

Predicted International Trade Flows for any future year $2012+t=$ (Observed or Estimated International Trade Flows for year 2012) $\times(1.04)^{t}$.

For IFSTEM-Oman Model application, the annual growth rate for the socio-economic variables $E_{i}$ and $A_{i j}$ are computed as follows:

$E_{i}$ For year $2012+t=\left(E_{i}\right.$ for year 2012) $\times(1.04)^{t}$;

$A_{i j}$ For year $2012+t=\left(A_{i j}\right.$ for year 2012) $\times(1.04)^{t}$.

For example, the prediction for 2040 will use

$E_{i} \quad$ For year $2040=\left(E_{i}\right.$ for year 2012 $) \times(1.04)^{28}$;

$A_{i j}$ For year $2040=\left(A_{i j}\right.$ for year 2012) $\times(1.04)^{28}$.

\subsection{Predicted International Trade Flows for Oman (2012-2040)}

Table A2-1 in the Appendix 2 shows the results of the predicted international trade flows for all exports, imports, and re-exports for Oman for the reference scenario and the proposed four enhancement scenarios indicated in Section 4 above, for all the years of the analysis period from 2012 through 2040. As indicated in Table A2-1 Scenario 1 is assumed to be implemented in 2015, Scenario 
2 in 2016, Scenario 3 in 2017, and Scenario 4 in 2018.

Below are Figures 2-4 that show the predicted international trade flow results of Table A2-1 in graphic formats easy to visualize and analyze. The prediction results of the IFSTEM-Oman Model as depicted in Table A2-1 and Figures 2-4 are essentially logical, internally consistent and reasonable. These predictions are satisfactory for the purposes of analysis in this paper, given the limited input data and estimates for this application. As indicated above, if and when more detailed data and estimates become available, the model is flexible, and appropriate to produce more detailed and refined results accordingly.

In all cases, various international researchers and practitioners including the Authors have already established that the IFSTEM simultaneous transportation equilibrium models, such as the model adopted in this Paper, are able to produce better results than other commonly used models and analysis techniques worldwide such as trend analysis and the sequential traditional transport planning models when applied to similar situation of input data and estimates. This is due to various distinctive features of the simultaneous IFSTEM model mainly its ability to predict increases in total international trade flows within the model, and its internal consistency of predictions of flows and costs, unlike the sequential models. The references cited in the second progress report of the Paper clearly demonstrated these distinctive advantages of IFSTEM.

Figure 2 shows the predicted high trends and rates of increase of international trade flows during the analysis period for the 4 alternative enhancement scenarios compared to the reference scenario. The graph clearly shows a significant increase of all 4 enhancement scenarios compared to the reference scenario. Comparing among the 4 alternative enhancement scenarios, as expected, Scenarios 3 and 4 exhibit relatively the highest increases in absolute value and in terms of the rate of increase of international trade flows compared to scenarios 1 and 2. Comparing between Scenarios 1 and 2 we can see that as expected the relative improvement of Scenario 2 over Scenario 1 is minimal.

Figure 3 shows the percent increase of international trade flows for the various enhancement scenarios compared with the reference scenario as of 2012 (for example for Scenario 1,

the percent increase $=\frac{(162012098-37112001)}{37112001}+1=437 \%$ as well as its predictions at the target year of 2040 , the percent increase $=\frac{(162012098-110532300)}{110532300}+1=147 \%$. Figure 4 shows the absolute values of international trade flows at 2020, 2030 and 2040 for all 4 enhancement scenarios as well as the reference scenario. These figures show that the expected predictions of international trade for Scenario 4 at 2040 would reach around 187 million tons compared with the current volume of around 37 million tons, i.e., Scenario 4 would reach around 504\% higher compared to the current flows in 2012. The difference would be around 70\% higher for Scenario 4 


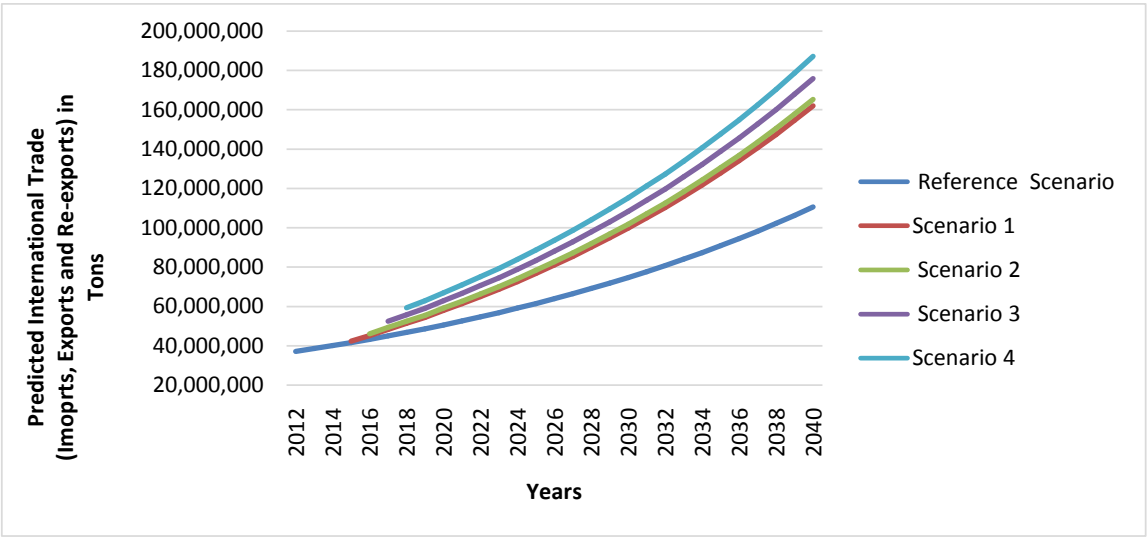

Figure 2. Predicted international trade (imports, exports and re-exports) in tons for reference scenario and 4 enhancement scenarios for 2012-2040.

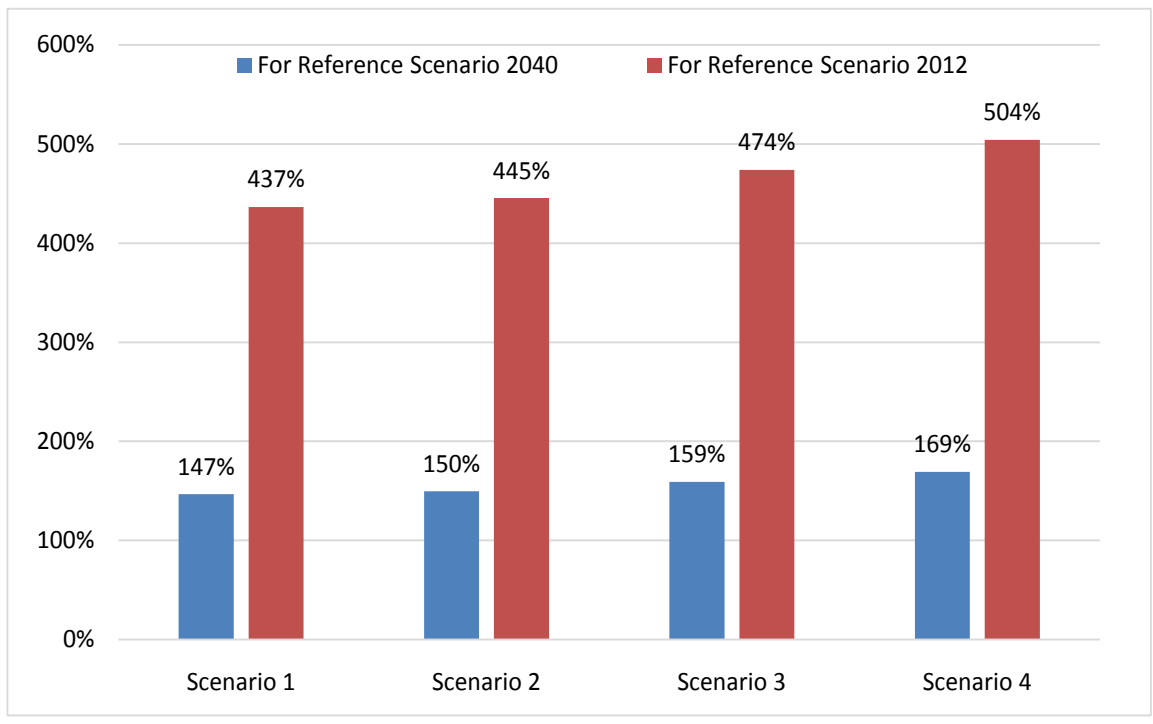

Figure 3. Predicted percent increase of international trade (imports, exports and re-exports) by 2040 for 4 enhancement scenarios compared with the reference scenario for 2012 and 2040 .

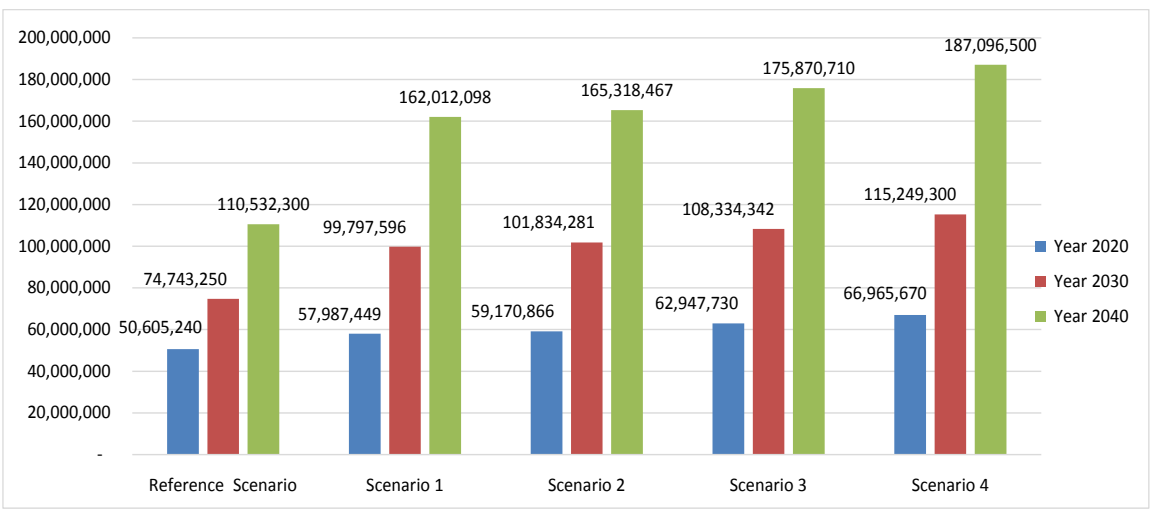

Figure 4. Comparison of predicted international trade (imports, exports and re-exports) in tons between reference scenario and 4 proposed scenarios for years 2020, 2030, and 2040. 
compared to the predicted flows by 2040 if we do nothing until that time (i.e., around 110 Million tons).

It is worth noting that Scenario 4 implies that international maritime transport times and costs to Omani ports would be $20 \%$ less compared to that for Jebel Ali Port. Hence, for this Scenario 4 to be realized it would need extensive improvements and enhancements of competitiveness and integration of Omani ports relative to UAE ports. Of course, in reality, UAE as well as world ports are constantly improving and enhancing.

\subsection{Predicted Total Cost per Ton of International Trade Flows}

Table A2-2 in the Appendix 2 and Figure 5 and Figure 6 below show the comparison among the reference scenario and the four proposed enhancement Scenarios 1, 2, 3 and 4 with respect to the total cost per ton in USD. The figures show that the total cost per ton, decreased from an estimated 254 USD per ton for the reference scenario to around a predicted 202 USD per ton for Scenario 4. That is the cost per ton is expected to be decreased by more than $20 \%$ for enhancement Scenario 4 compared to the reference scenario (0). This should reflect significant savings to the Omani economy.

\subsection{Predicted Average Total Trip Time of International Trade Flows (in Days)}

Table A2-3 in the Appendix 2 and Figure 7 and Figure 8 depicted below show the comparison among the reference scenario and the four proposed enhancement scenarios with respect to the average Total Trip Time (in days) over the analysis period 2012-2040. The figures clearly indicate a reduction of this average trip time from 42 days for the reference scenario to 32 days for Scenario 4 . That is around 25\% decrease of average total trip time. Again this should result in significant savings in trip time for international trade for Oman and hence significant benefits to the Omani economy.

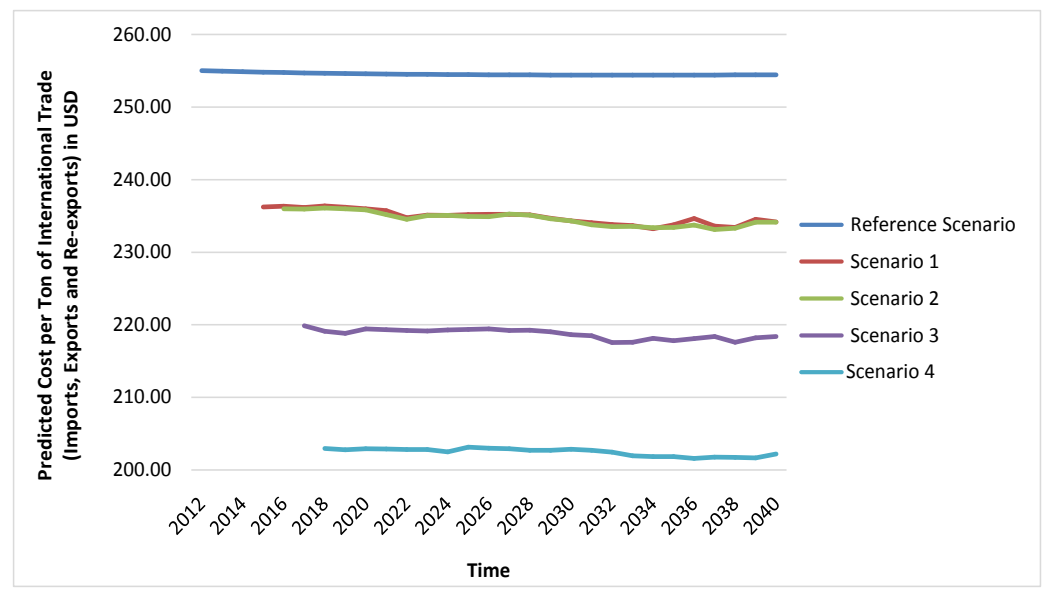

Figure 5. Predicted total cost per ton of international trade (imports, exports and Re-exports) in USD for reference scenario and 4 scenarios for 2012-2040. 


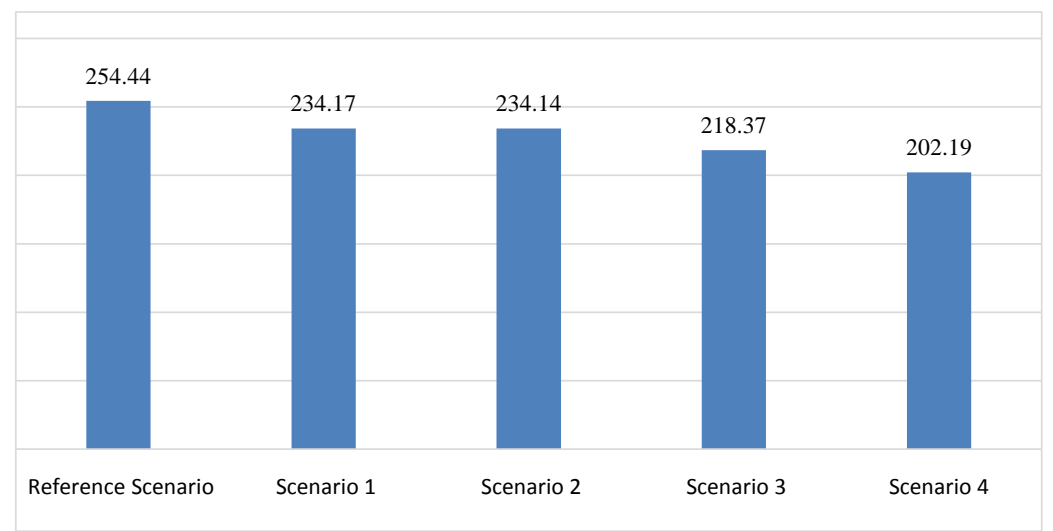

Figure 6. Comparison of predicted total cost per ton in USD for international trade (imports, exports and re-exports) between the reference scenario and the 4 proposed scenarios for year 2040.

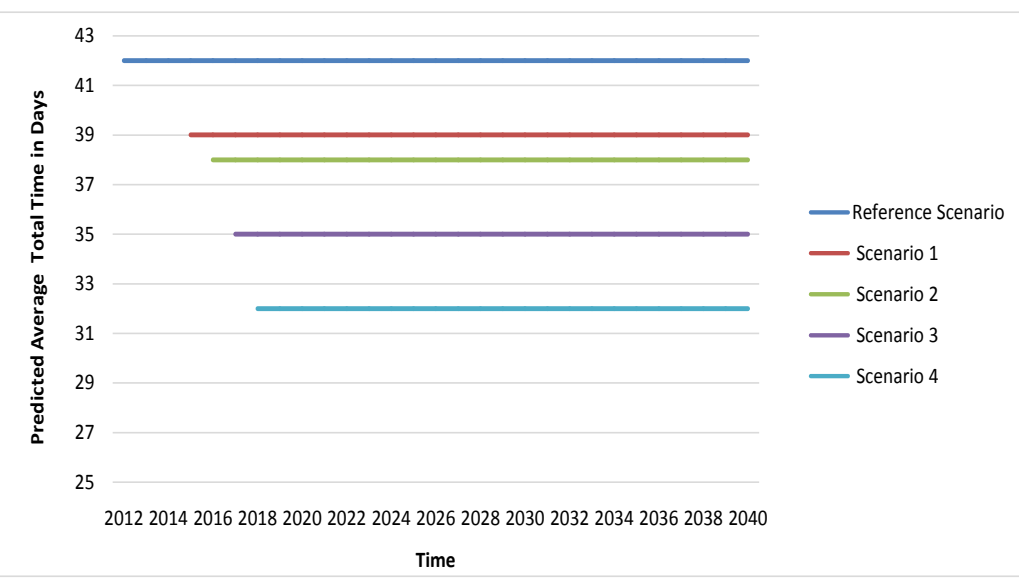

Figure 7. Predicted average total time in days of international trade (imports, exports and re-exports) for reference scenario and 4 enhancement scenarios for 2012-2040.

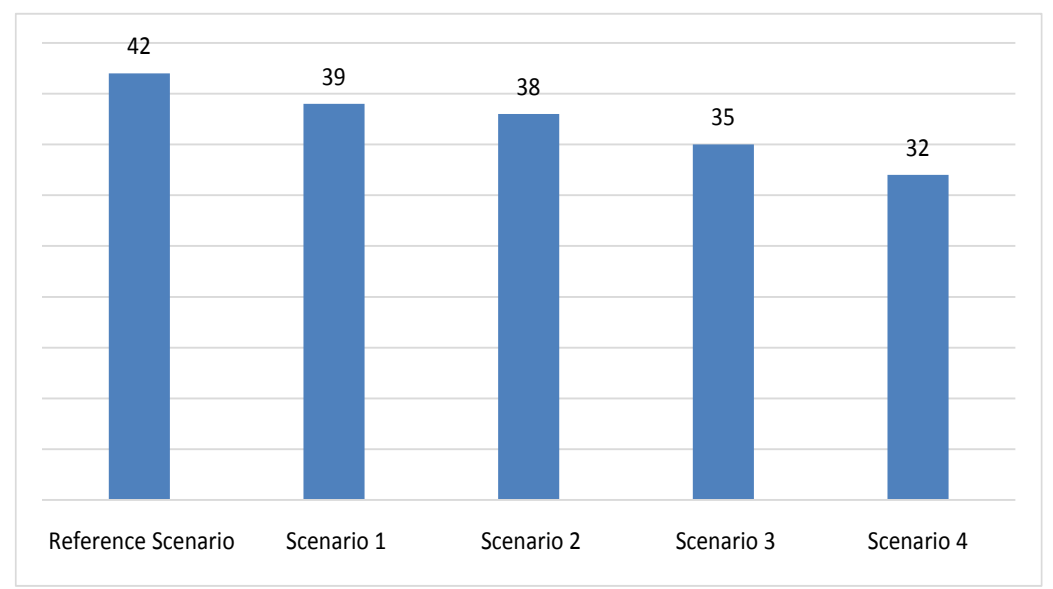

Figure 8. Comparison of average total time in days for international trade (imports, exports and re-exports) between the reference scenario and the 4 proposed enhancement scenarios for year 2040. 


\section{Conclusions}

- The proposed alternative enhancement scenarios were 4 nested scenarios, i.e., each scenario included the previous one plus an additional enhancement. Scenario 1 involved reducing the number of documents from 8 to 4 , and Scenario 2 involved Scenario 1 plus reducing the time for port and terminal handling to 1 day (instead of 2 days for imports and 3 days for exports as estimated for 2012 by the World Bank trading across borders report 2013). Scenario 3 involved Scenarios 1 and 2 plus reducing the international maritime transport times and costs by $20 \%$ (i.e., to become equal to that of the UAE according to the application assumptions), and Scenario 4 involved Scenarios 1 and 2 plus reducing the international maritime transport times and costs by $40 \%$ (i.e., to become $20 \%$ less than that of UAE according to the application assumptions). These 4 enhancement scenarios were analyzed against and compared with scenario (0), i.e., the reference "do nothing" scenario.

- The analysis has been achieved in two stages: The first stage involved the prediction of international trade flows (imports, exports and re-exports), times and costs that would result from the application of the 4 alternative enhancement scenarios during the analysis period through the target year of 2040; The second stage involved the assessment of the financial and economic feasibility of the implementation of the 4 alternative enhancement scenarios based on the predictions of stage one and assessment methodology of stage two. The prediction and assessment results were analyzed against the reference scenario.

- The predictions were obtained using an advanced International Freight Simultaneous Transport Equilibrium Model adapted for Oman, i.e., IFSTEM-Oman Model. This IFSTEM-Oman Model belongs to the class of the distinguished simultaneous transport planning equilibrium models. The simultaneous planning models were developed over the past 50 years to overcome a few inherent deficiencies of the well-known traditional sequential transport planning models widely used until today by the majority of consultants and authorities worldwide.

- Several recognized international researchers and practitioners over the previous few decades, including the authors of this paper, have established that the simultaneous equilibrium models consistently produce better predictions (i.e., internally consistent) compared to the sequential transport planning models. This is of course true when both models are compared under similar situations of input data availability and/or limitations.

- The main advantages of the IFSTEM-Oman Model utilized in this paper are that it can predict the expected increase in the total international trade flows within the model in a simultaneous manner replicating the decision making process of the exporter and the importer, unlike the sequential modelling process that does not properly replicate the decision making process of the 
importer and the exporter and cannot predict the total international trade flows internally within the modelling process. Hence the IFSTEM-Oman Model predictions of international trade flows, times and costs are relatively more accurate and are internally consistent, unlike the sequential models.

- The prediction results revealed that the estimated international trade flows (imports, exports and re-exports) for Oman for Scenario 4 would increase by more than $504 \%$ by 2040 ( i.e., around 187 million tons) compared to the present situation of the base year 2012 (i.e., around 37 million tons). This increase would represent around $70 \%$ compared to the "do nothing" reference scenario by the year 2040 (i.e., around 110 million tons) assuming that the average increase of international trade flows in the "do nothing" case would be around $4 \%$ annually during the analysis period from 2012 to 2040 . The predictions of average total trip time and total cost per ton revealed an estimated decrease for Scenario 4 compared to the reference scenario by around $25 \%$ and $20 \%$ respectively. These results are internally consistent and represented reasonably significant improvements compared to the "do nothing" reference scenario.

\section{References}

[1] Safwat, K.N.A. and Walton, C.M. (1988) Computational Experience with and Application of a Simultaneous Transportation Equilibrium Model to Urban Travel in Austin, Texas: Computational Results. Transportation Research B, 22B, 457-467.

[2] Safwat, K.N.A. and Hasan, M.K. (1989) Computational Experience with Simultaneous Transportation Equilibrium Model under Varying Parameters. Transportation Research Record 1251, TRB, National Research Council, Washington DC, 17-23.

[3] Safwat, K.N.A. (1987) Application of Simultaneous Transportation Equilibrium Model to Intercity Passenger Travel in Egypt. Transportation Research Record 1120, TRB, National Research Council, Washington DC, 52-59.

[4] Safwat, K.N.A. (1987) Computational Experience with Application of Simultaneous Transportation Equilibrium Model to Intercity Passenger Travel in Egypt. Transportation Research Record 1120, TRB, National Research Council, Washington DC, 60-67.

[5] Safwat, K.N.A. and Magnanti, T.L. (1988) A Combined Trip Generation, Trip Distribution, Modal Split and Traffic Assignment Model. Transportation Science, 22, 14-30. https://doi.org/10.1287/trsc.22.1.14

[6] Hasan, M.K. (1991) Comparative Analysis of Alterative Simultaneous Transportation Network Equilibrium Models. Ph.D. Dissertation, Texas A\&M University, College Station, TX.

[7] Hasan, M.K. and Al-Gadhi, S.A. (1998) Comparison of Simultaneous and Sequential Transportation Network Equilibrium Models, Application to Riyadh, Saudi Arabia, Transportation Research Record, 1645, 127-132. https://doi.org/10.3141/1645-16

[8] Hasan, M.K. and Safwat, K.N.A. (2000) Comparison of Two Transportation Network Equilibrium Modeling Approaches. Journal of Transportation Engineering, 126, 35-40. https://doi.org/10.1061/(ASCE)0733-947X(2000)126:1(35) 
[9] Florian, M. (1984) An Introduction to Network Models Used in Transportation Planning. In: Florian, M., Ed., Transportation Planning Models, North Holland, Amsterdam, 137-152.

[10] Florian, M. (1986) Nonlinear Cost Network Models in Transportation Analysis. In: Gallo, G. and Sandi, C., Eds., Netflow at Pisa. Mathematical Programming Studies, Vol. 26. Springer, Berlin, Heidelberg, 167-196. https://doi.org/10.1007/BFb0121092

[11] Samuelson, P.A. (1952) Spatial Price Equilibrium and Linear Programming. Amer. Econ. Rev, 42, 283-303.

[12] Takayama, T. and Judge, G.G. (1964) Equilibrium among Spatially Separated Markets: A Reformulation. Econometrica, 32, 510-524. https://doi.org/10.2307/1910175

[13] Takayama, T. and Judge, G.G. (1970) Alternative Spatial Price Equilibrium Models. J. Region. Sci, 10, 1-12.

[14] Florian, M. and Los, M. (1982) A New Look at Static Price Equilibrium Models. Regional Science and Urban Economics, 12, 579-597. https://doi.org/10.1016/0166-0462(82)90008-4

[15] Friesz, T.L., Tobin, R.L. and Harker, P.T. (1983) Predictive Intercity Freight Network Models: The State of the Art. Transportation Research Part A: General, 17, 409-417. https://doi.org/10.1016/0191-2607(83)90161-9

[16] Roberts, P.O. (1976) Transport Planning: Models for Developing Countries. Unpublished Ph.D. Dissertation, Northwestern University, Evanston, IL.

[17] Kresge, D.T. and Roberts, P.O. (1971) Systems Analysis and Simulation Models. In: Meyer, J.D., Ed., Techniques of Transport Planning, The Brookings Institute, Washington DC.

[18] McGinnis, L.F., Sharp, G.P. and Yu, D.H.C. (1981) Procedures for Multi-State, Multi-Mode Analysis: Vol. IV, Transportation Modeling and Analysis, U.S. D.O.T. Report No. DOT-OST-80050-17/V.N.

[19] Jones, P.S. and Sharp, G.P. (1979) Multi-Mode Intercity Freight Transportation Planning for Underdeveloped Regions. Proceedings of the 20 th Annual Meeting, Transportation Research Forum.

[20] Sharp, G.P. (1979) A Multi-Commodity Intermodal Transportation Model. Proceedings of the 20 th Annual Meeting, Transportation Research Forum.

[21] Friesz, T.L., Viton, P.A. and Tobin, R.L. (1985) Economic and Computational Aspects of Freight Network Equilibrium Models: A Synthesis. Journal of Regional Science, 25, 29-49. https://doi.org/10.1111/j.1467-9787.1985.tb00292.x

[22] Friesz, T.L. and Harker, P.T. (1985) Freight Network Equilibrium: A Review of the State of the Art. In: Daughety, A.F., Ed., Analytical Studies in Transport Economics, Chap. 7, Cambridge University Press, Cambridge.

[23] Friesz, T.L., Gottfried, J.A. and Morlok, E.K. (1986) A Sequential Shipper-Carrier Network Model for Predicting Freight Flows. Transportation Science, 20, 80-91. https://doi.org/10.1287/trsc.20.2.80

[24] Harker, P.T. and Friesz, T.L. (1986) Prediction of Intercity Freight Flows, I: Theory. Transportation Research Part B: Methodological, 20, 139-153. https://doi.org/10.1016/0191-2615(86)90004-4

[25] Harker, P.T. and Friesz, T.L. (1986) Prediction of Intercity Freight Flows II: Mathematical Formulations. Transportation Research Part B: Methodological, 20, 155-174. https://doi.org/10.1016/0191-2615(86)90005-6

[26] Guelat, A., Florian, M. and Crainic, T.G. (1990) A Multimode Multiproduct Network Assignment Model for Strategic Planning of Freight Flows. Transportation 
Science, 24, 25-39. https://doi.org/10.1287/trsc.24.1.25

[27] Safwat, K.N.A. (1982) The Simultaneous Prediction of Equilibrium on Large-Scale Networks: A Unified Consistent Methodology for Transportation Planning. Ph.D. Dissertation, Massachusetts Institute of Technology, Cambridge, MA.

[28] Moavenzadeh, F., Markow, M., Brademeyer, B. and Safwat, K.N.A. (1983) A Methodology for Intercity Transportation Planning in Egypt. Transportation Research Part A: General, 17, 481-491. https://doi.org/10.1016/0191-2607(83)90168-1

[29] (1986) Updating and Application of the Intercity Transportation Model. Final Report, CU/MIT Technology Adaptation Program, Development Research and Technological Planning Center, Cairo University, Cairo.

[30] Safwat, K., Nabil, A. and Hasan, M.K. (2004) Predicting International Freight Flows for Trade: Simultaneous Multimodal, Multi-Commodity, Network Equilibrium Model. Transportation Research Record, 1882, 129-139.

[31] Hasan, M.K. (2009) Multimodal, Multicommodity International Freight Simultaneous Transportation Equilibrium Model. Telecommunication Systems, 40, 39-54.

[32] Mathisena, T.A. and Hanssena, T.S. (2014) The Academic Literature on Intermodal Freight Transport. Transportation Research Procedia, 3, 611-620. https://doi.org/10.1016/j.trpro.2014.10.040

[33] Duan, L., Tavasszy, L. and Peng, Q. (2017) Freight Network Design with Heterogeneous Values of Time. Transportation Research Procedia, 25, 1144-1150. https://doi.org/10.1016/j.trpro.2017.05.127

[34] Safwat, K.N.A. and Brademeyer, B. (1988) Proof of Global Convergence of an Efficient Algorithm for Predicting Trip Generation, Trip Distribution, Modal Split and Traffic Assignment Simultaneously on Large-Scale Networks. Computers \& Mathematics with Applications, 16, 269-277.

https://doi.org/10.1016/0898-1221(88)90143-5 


\section{Appendix 1}

\section{Input Data for IFSTEM-Oman Model}

Table A1-1. Estimates of documents, times and costs of a typical 20-Ft container for exports and imports, from the World Bank (WB) Report 2013 for Oman.

\begin{tabular}{|c|c|c|c|c|}
\hline \multicolumn{3}{|c|}{ Oman } & & \\
\hline Indicator & $\begin{array}{l}\text { Export and } \\
\text { Re-Export }\end{array}$ & Import & & \\
\hline Number of documents & 8 & 8 & & \\
\hline Time (days) & 10 & 9 & & \\
\hline \multirow[t]{2}{*}{ Cost (US\$ per container 20 -foot) } & 745 & 680 & & \\
\hline & \multicolumn{2}{|c|}{ Export and Re-Export } & \multicolumn{2}{|c|}{ Import } \\
\hline Procedures & Time (days) & Cost (US\$) & Time (days) & Cost (US\$) \\
\hline Documents preparation & 5 & 285 & 5 & 250 \\
\hline $\begin{array}{l}\text { Customs clearance and technical } \\
\text { control }\end{array}$ & 1 & 65 & 1 & 65 \\
\hline Ports and terminal handling & 3 & 135 & 2 & 105 \\
\hline $\begin{array}{l}\text { Inland transportation and } \\
\text { handling }\end{array}$ & 1 & 260 & 1 & 260 \\
\hline Totals & 10 & 745 & 9 & 680 \\
\hline Documents to export & $\begin{array}{l}\text { Documents to } \\
\text { import }\end{array}$ & & & \\
\hline Bill of lading & Bill of lading & & & \\
\hline Certificate of origin & Cargo release order & & & \\
\hline Commercial invoice & Certificate of origin & & & \\
\hline Customs export declaration & Commercial invoice & & & \\
\hline Packing list & $\begin{array}{l}\text { Customs import } \\
\text { declaration }\end{array}$ & & & \\
\hline Shipping note (pre-advice form) & Packing list & & & \\
\hline Technical standard certificate & $\begin{array}{l}\text { Technical standard } \\
\text { certificate }\end{array}$ & & & \\
\hline Terminal handling receipts & $\begin{array}{l}\text { Terminal handling } \\
\text { receipts }\end{array}$ & & & \\
\hline
\end{tabular}


Table A1-2. Estimates of documents, times and costs of a Typical 20-Ft container for exports and imports, from the World Bank (WB) Report 2013 for United Arab Emirates.

\begin{tabular}{|c|c|c|c|c|}
\hline \multicolumn{3}{|c|}{ United Arab Emirates } & & \\
\hline Indicator & Export and Re-Export & Import & & \\
\hline Number of documents & 4 & 5 & & \\
\hline Time (days) & 7 & 7 & & \\
\hline \multirow[t]{2}{*}{ Cost (US\$ per container 20-foot) } & 630 & 590 & & \\
\hline & \multicolumn{2}{|c|}{ Export and Re-Export } & \multicolumn{2}{|c|}{ Import } \\
\hline Procedures & Time (days) & Cost (US\$) & $\begin{array}{l}\text { Time } \\
\text { (days) }\end{array}$ & $\begin{array}{l}\text { Cost } \\
\text { (US\$) }\end{array}$ \\
\hline Documents preparation & 4 & 215 & 4 & 175 \\
\hline $\begin{array}{l}\text { Customs clearance and technical } \\
\text { control }\end{array}$ & 1 & 30 & 1 & 30 \\
\hline Ports and terminal handling & 1 & 180 & 1 & 180 \\
\hline Inland transportation and handling & 1 & 205 & 1 & 205 \\
\hline Totals & 7 & 630 & 7 & 590 \\
\hline Documents to export & Documents to import & & & \\
\hline Bill of lading & Bill of lading & & & \\
\hline Certificate of origin & Certificate of origin & & & \\
\hline Commercial invoice & Commercial invoice & & & \\
\hline \multirow[t]{2}{*}{ Customs export declaration } & $\begin{array}{l}\text { Customs import } \\
\text { declaration }\end{array}$ & & & \\
\hline & Packing list & & & \\
\hline
\end{tabular}

Table A1-3. Land transport and handling time (Days) and cost (US\$/TEU) from the Muscat to the 5 points of entries/exits.

\begin{tabular}{|c|c|c|c|c|c|c|c|}
\hline & \multirow{2}{*}{ Point of Entry } & \multicolumn{2}{|c|}{ Import } & \multicolumn{2}{|c|}{ Export } & \multicolumn{2}{|c|}{ Re-Export } \\
\hline & & Time & Cost & Time & Cost & Time & $\operatorname{Cos}$ \\
\hline & Salalah & 2 & 320 & 2 & 320 & 2 & 320 \\
\hline \multirow[t]{4}{*}{ Oman } & S Qaboos & 1 & 200 & 1 & 200 & 1 & 200 \\
\hline & Sohar & 1 & 250 & 1 & 250 & 1 & 250 \\
\hline & Wajajah & 1 & 270 & 1 & 270 & 1 & 270 \\
\hline & Wadi Jizzi & 1 & 270 & 1 & 270 & 1 & 270 \\
\hline
\end{tabular}

Table A1-4. Land transport and handling time (Days) and cost (US\$/TEU) from Wajajah or Wadi Jizzi to entries/exits land border to given Arab countries.

\begin{tabular}{ccccccc}
\hline & \multicolumn{2}{c}{ Import } & \multicolumn{2}{c}{ Export } & \multicolumn{2}{c}{ Re-Export } \\
\hline UAE & Time & Cost & Time & Cost & Time & Cost \\
SAU & 2 & 235 & 2 & 235 & 2 & 235 \\
Qatar & 4 & 835 & 4 & 835 & 4 & 835 \\
Bahrain & 4 & 835 & 4 & 835 & 4 & 835 \\
Kuwait & 4 & 835 & 4 & 835 & 4 & 835 \\
Jordan & 4 & 835 & 4 & 835 & 4 & 835 \\
Syria & 5 & 835 & 5 & 835 & 5 & 835 \\
Iraq & 7 & 1335 & 7 & 1335 & 7 & 1335 \\
Yemen & 5 & 835 & 5 & 835 & 5 & 835 \\
& 2 & 320 & 320 & 320 & 2 & 320 \\
\hline
\end{tabular}


Table A1-5. A sample of 20 out of 140 countries for international maritime transport times (in days) and costs (in USD per 20-ft container) for 2012 for Mina Sultan Qaboos.

\begin{tabular}{|c|c|c|c|c|c|}
\hline No. & Country & Import time & Export time & Import cost & Export cost \\
\hline 1 & Afghanistan & 12 & 16 & 800 & 1200 \\
\hline 2 & Albania & 32 & 30 & 1400 & 1100 \\
\hline 3 & Algeria & 28 & 30 & 1600 & 1400 \\
\hline 4 & Angola & 30 & 32 & 1700 & 1600 \\
\hline 5 & Argentina & 35 & 40 & 2100 & 1900 \\
\hline 6 & Australia & 40 & 45 & 1800 & 1900 \\
\hline 7 & Austria & 35 & 40 & 2000 & 1800 \\
\hline 8 & Azerbaijan & 28 & 30 & 1200 & 1400 \\
\hline 9 & Bahamas & 24 & 26 & 1100 & 1300 \\
\hline 10 & Bahrain & 14 & 16 & 600 & 800 \\
\hline 11 & Bangladesh & 16 & 18 & 800 & 900 \\
\hline 12 & Belarus & 24 & 28 & 900 & 1100 \\
\hline 13 & Belgium & 26 & 30 & 1250 & 1350 \\
\hline 14 & Benin & 35 & 40 & 2000 & 1800 \\
\hline 15 & Bosnia Herzegovina & 40 & 45 & 1800 & 1900 \\
\hline 16 & Botswana & 30 & 35 & 1100 & 1200 \\
\hline 17 & Brazil & 55 & 60 & 2200 & 2400 \\
\hline 18 & Bulgaria & 50 & 55 & 2100 & 2300 \\
\hline 19 & Burundi & 50 & 55 & 2100 & 2300 \\
\hline 20 & Cambodia & 55 & 60 & 2200 & 2400 \\
\hline
\end{tabular}

Table A1-6. The five highest volume commodities crossing the five entry/exit points.

\begin{tabular}{cl}
\hline HS_4DG & \multicolumn{1}{c}{ HS_4DG Description } \\
\hline 207 & Meat and edible offal, of the poultry of heading 01.05, fresh, chilled or frozen. \\
1511 & Palm oil and its fractions, whether or not refined, but not chemically modified. \\
7304 & $\begin{array}{l}\text { Tubes, pipes and hollow profiles, seamless, of iron (other than cast iron) or steel. } \\
7308\end{array}$ \\
& $\begin{array}{l}\text { Structures (excluding prefabricated buildings of heading 94.06) and parts of structures } \\
\text { (for example, bridges and bridge-sections, lock-gates, towers, lattice masts, roofs, } \\
\text { roofing frame-works, doors and windows and their frames and thresholds for doors, }\end{array}$ \\
& $\begin{array}{l}\text { Air conditioning machines, comprising a motor-driven fan and elements for changing } \\
\text { the temperature and humidity, including those machines in which the humidity can't } \\
\text { be separately regulated. }\end{array}$
\end{tabular}




\section{Appendix 2}

\section{Prediction Results for IFSTEM-Oman Model}

Table A2-1. Predicted international trade (imports, exports and re-exports) in tons for reference scenario and 4 scenarios for 2012-2040.

\begin{tabular}{|c|c|c|c|c|c|}
\hline Year & $\begin{array}{l}\text { The international } \\
\text { trade in Tons for } \\
\text { reference scenario }\end{array}$ & $\begin{array}{l}\text { The } \\
\text { international } \\
\text { trade in Tons } \\
\text { for Scenario } 1\end{array}$ & $\begin{array}{c}\text { The } \\
\text { international } \\
\text { trade in Tons for } \\
\text { Scenario } 2\end{array}$ & $\begin{array}{l}\text { The } \\
\text { international } \\
\text { trade in Tons } \\
\text { for Scenario } 3\end{array}$ & $\begin{array}{c}\text { The } \\
\text { international } \\
\text { trade in Tons } \\
\text { for Scenario } 4\end{array}$ \\
\hline 2012 & $37,112,001$ & & & & \\
\hline 2013 & $38,573,610$ & & & & \\
\hline 2014 & $40,094,540$ & & & & \\
\hline 2015 & $41,677,192$ & $42,306,557$ & & & \\
\hline 2016 & $43,324,030$ & $45,204,958$ & $46,127,508$ & & \\
\hline 2017 & $45,037,530$ & $48,362,077$ & $49,349,058$ & $52,498,998$ & \\
\hline 2018 & $46,820,380$ & $51,407,063$ & $52,456,186$ & $55,804,454$ & $59,366,440$ \\
\hline 2019 & $48,675,320$ & $54,432,832$ & $55,543,706$ & $59,089,049$ & $62,860,690$ \\
\hline 2020 & $50,605,240$ & $57,987,449$ & $59,170,866$ & $62,947,730$ & $66,965,670$ \\
\hline 2021 & $52,613,080$ & $61,440,042$ & $62,693,921$ & $66,695,660$ & $70,952,830$ \\
\hline 2022 & $54,701,890$ & $65,041,367$ & $66,368,742$ & $70,605,045$ & $75,111,750$ \\
\hline 2023 & $56,874,960$ & $68,689,661$ & $70,091,490$ & $74,565,415$ & $79,324,910$ \\
\hline 2024 & $59,135,620$ & $72,661,872$ & $74,144,767$ & $78,877,412$ & $83,912,140$ \\
\hline 2025 & $61,487,290$ & $76,789,335$ & $78,356,464$ & $83,357,940$ & $88,678,660$ \\
\hline 2026 & $63,933,620$ & $81,089,265$ & $82,744,148$ & $88,025,689$ & $93,644,350$ \\
\hline 2027 & $66,478,420$ & $85,480,412$ & $87,224,910$ & $92,792,457$ & $98,715,380$ \\
\hline 2028 & $69,125,580$ & $90,144,317$ & $91,983,997$ & $97,855,316$ & $104,101,400$ \\
\hline 2029 & $71,879,110$ & $94,911,251$ & $96,848,215$ & $103,030,016$ & $109,606,400$ \\
\hline 2030 & $74,743,250$ & $99,797,596$ & $101,834,281$ & $108,334,342$ & $115,249,300$ \\
\hline 2031 & $77,722,500$ & $105,069,972$ & $107,214,257$ & $114,057,720$ & $121,338,000$ \\
\hline 2032 & $80,821,330$ & $110,254,975$ & $112,505,077$ & $119,686,252$ & $127,325,800$ \\
\hline 2033 & $84,044,570$ & $115,941,351$ & $118,307,501$ & $125,859,044$ & $133,892,600$ \\
\hline 2034 & $87,397,110$ & $121,806,282$ & $124,292,124$ & $132,225,664$ & $140,665,600$ \\
\hline 2035 & $90,884,150$ & $127,908,563$ & $130,518,942$ & $138,849,938$ & $147,712,700$ \\
\hline 2036 & $94,511,100$ & $134,114,496$ & $136,851,526$ & $145,586,730$ & $154,879,500$ \\
\hline 2037 & $98,283,430$ & $140,691,046$ & $143,562,291$ & $152,725,842$ & $162,474,300$ \\
\hline 2038 & $102,207,100$ & $147,425,281$ & $150,433,960$ & $160,036,128$ & $170,251,200$ \\
\hline 2039 & $106,287,900$ & $154,697,604$ & $157,854,698$ & $167,930,530$ & $178,649,500$ \\
\hline 2040 & $110,532,300$ & $162,012,098$ & $165,318,467$ & $175,870,710$ & $187,096,500$ \\
\hline
\end{tabular}


Table A2-2. Predicted cost per ton of international trade (imports, exports and re-exports) in USD for reference scenario and 4 scenarios for 2012-2040.

\begin{tabular}{|c|c|c|c|c|c|}
\hline Year & $\begin{array}{c}\text { Total cost per } \\
\text { Ton (USD) for } \\
\text { reference sce- } \\
\text { nario }\end{array}$ & $\begin{array}{l}\text { Total cost per } \\
\text { Ton (USD) for } \\
\text { Scenario } 1\end{array}$ & $\begin{array}{l}\text { Total cost per } \\
\text { Ton (USD) for } \\
\text { Scenario } 2\end{array}$ & $\begin{array}{l}\text { Total cost per } \\
\text { Ton (USD) } \\
\text { for Scenario } 3\end{array}$ & $\begin{array}{c}\text { Total cost per } \\
\text { Ton (USD) for } \\
\text { Scenario } 4\end{array}$ \\
\hline 2012 & 255.02 & & & & \\
\hline 2013 & 254.95 & & & & \\
\hline 2014 & 254.88 & & & & \\
\hline 2015 & 254.82 & 236.23 & & & \\
\hline 2016 & 254.76 & 236.36 & 235.987 & & \\
\hline 2017 & 254.71 & 236.17 & 235.9573 & 219.859 & \\
\hline 2018 & 254.66 & 236.39 & 236.096 & 219.0882 & 202.9488 \\
\hline 2019 & 254.62 & 236.18 & 235.9646 & 218.8203 & 202.7789 \\
\hline 2020 & 254.59 & 235.98 & 235.8499 & 219.4151 & 202.9237 \\
\hline 2021 & 254.56 & 235.74 & 235.1868 & 219.3325 & 202.8828 \\
\hline 2022 & 254.53 & 234.75 & 234.5462 & 219.2228 & 202.8038 \\
\hline 2023 & 254.50 & 235.10 & 235.0502 & 219.1215 & 202.8226 \\
\hline 2024 & 254.48 & 235.08 & 235.0682 & 219.2917 & 202.4824 \\
\hline 2025 & 254.47 & 235.17 & 234.9347 & 219.3556 & 203.1174 \\
\hline 2026 & 254.45 & 235.23 & 234.9049 & 219.4358 & 202.9796 \\
\hline 2027 & 254.44 & 235.23 & 235.2696 & 219.2267 & 202.9078 \\
\hline 2028 & 254.43 & 235.16 & 235.0936 & 219.2464 & 202.6981 \\
\hline 2029 & 254.42 & 234.68 & 234.6168 & 219.034 & 202.6909 \\
\hline 2030 & 254.42 & 234.33 & 234.3177 & 218.6331 & 202.8236 \\
\hline 2031 & 254.41 & 234.08 & 233.7588 & 218.4723 & 202.6829 \\
\hline 2032 & 254.41 & 233.82 & 233.5228 & 217.5586 & 202.4453 \\
\hline 2033 & 254.41 & 233.65 & 233.5644 & 217.5911 & 201.9525 \\
\hline 2034 & 254.41 & 233.22 & 233.3596 & 218.1222 & 201.8384 \\
\hline 2035 & 254.41 & 233.77 & 233.4182 & 217.8148 & 201.8288 \\
\hline 2036 & 254.42 & 234.63 & 233.728 & 218.0744 & 201.5846 \\
\hline 2037 & 254.42 & 233.58 & 233.114 & 218.3752 & 201.7465 \\
\hline 2038 & 254.43 & 233.42 & 233.2973 & 217.5719 & 201.7378 \\
\hline 2039 & 254.43 & 234.53 & 234.1501 & 218.197 & 201.6447 \\
\hline 2040 & 254.44 & 234.17 & 234.1394 & 218.3735 & 202.1851 \\
\hline
\end{tabular}


Table A2-3. Predicted average total time in days of international trade (imports, exports and re-exports) for reference scenario and 4 scenarios for 2012-2040.

\begin{tabular}{|c|c|c|c|c|c|}
\hline Year & $\begin{array}{l}\text { Average times } \\
\text { in days for } \\
\text { reference } \\
\text { scenario }\end{array}$ & $\begin{array}{l}\text { Average times } \\
\text { in days for } \\
\text { Scenario } 1\end{array}$ & $\begin{array}{l}\text { Average times } \\
\text { in days for } \\
\text { Scenario } 2\end{array}$ & $\begin{array}{c}\text { Average times } \\
\text { in days for } \\
\text { Scenario } 3\end{array}$ & $\begin{array}{c}\text { Average times } \\
\text { in days for } \\
\text { Scenario } 4\end{array}$ \\
\hline 2012 & 42 & & & & \\
\hline 2013 & 42 & & & & \\
\hline 2014 & 42 & & & & \\
\hline 2015 & 42 & 39 & & & \\
\hline 2016 & 42 & 39 & 38 & & \\
\hline 2017 & 42 & 39 & 38 & 35 & \\
\hline 2018 & 42 & 39 & 38 & 35 & 32 \\
\hline 2019 & 42 & 39 & 38 & 35 & 32 \\
\hline 2020 & 42 & 39 & 38 & 35 & 32 \\
\hline 2021 & 42 & 39 & 38 & 35 & 32 \\
\hline 2022 & 42 & 39 & 38 & 35 & 32 \\
\hline 2023 & 42 & 39 & 38 & 35 & 32 \\
\hline 2024 & 42 & 39 & 38 & 35 & 32 \\
\hline 2025 & 42 & 39 & 38 & 35 & 32 \\
\hline 2026 & 42 & 39 & 38 & 35 & 32 \\
\hline 2027 & 42 & 39 & 38 & 35 & 32 \\
\hline 2028 & 42 & 39 & 38 & 35 & 32 \\
\hline 2029 & 42 & 39 & 38 & 35 & 32 \\
\hline 2030 & 42 & 39 & 38 & 35 & 32 \\
\hline 2031 & 42 & 39 & 38 & 35 & 32 \\
\hline 2032 & 42 & 39 & 38 & 35 & 32 \\
\hline 2033 & 42 & 39 & 38 & 35 & 32 \\
\hline 2034 & 42 & 39 & 38 & 35 & 32 \\
\hline 2035 & 42 & 39 & 38 & 35 & 32 \\
\hline 2036 & 42 & 39 & 38 & 35 & 32 \\
\hline 2037 & 42 & 39 & 38 & 35 & 32 \\
\hline 2038 & 42 & 39 & 38 & 35 & 32 \\
\hline 2039 & 42 & 39 & 38 & 35 & 32 \\
\hline 2040 & 42 & 39 & 38 & 35 & 32 \\
\hline
\end{tabular}

